Article

\title{
Study on Hydrogen Sensitivity of Ziegler-Natta Catalysts with Novel Cycloalkoxy Silane Compounds as External Electron Donor
}

\author{
Hongming Li ${ }^{1,2}$, Jing Wang ${ }^{1}$, Lei He ${ }^{1}$, Feng Nan ${ }^{1}$, Fan Wang ${ }^{1}$, Wantai Yang ${ }^{1}$, Mingge Zhang ${ }^{2}$, \\ Tianxu Sun ${ }^{2}$, Qigu Huang ${ }^{1, *}$ and Jianjun $\mathrm{Yi}^{2, *}$ \\ 1 State Key Laboratory of Chemical Resource Engineering, Key Laboratory of Carbon Fiber and Functional \\ Polymers, Ministry of Education, the College of Material Science and Engineering, Beijing University of \\ Chemical Technology, Beijing 100029, China; lihongming010@petrochina.com.cn (H.L.); \\ wangjing9917@126.com (J.W.); helei8818@163.com (L.H.); 2015200325@mail.buct.edu.cn (F.N.); \\ wangf2011@lzu.edu.cn (F.W.); yangwt@mail.buct.edu.cn (W.Y.) \\ 2 Petrochemical Research Institute, PetroChina, Beijing 102206, China; \\ zhangmingge@petrochina.com.cn (M.Z.); suntianxu@petrochina.com.cn (T.S.) \\ * Correspondence: huangqg@mail.buct.edu.cn (Q.H.); yijianjun@petrochina.com.cn (J.Y.); \\ Tel.: +86-10-6443-3856 (Q.H.); +86-10-8016-5456 (J.Y.)
}

Academic Editor: Alexander Böker

Received: 9 November 2016; Accepted: 8 December 2016; Published: 16 December 2016

\begin{abstract}
Two novel cycloalkoxy silane compounds (ED1 and ED2) were synthesized and used as the external electron donors (EEDs) in Ziegler-Natta catalysts with diethyl 2,3-diisopropylsuccinate as internal electron donor. The results indicated that the Ziegler-Natta catalysts using ED1 and ED2 as EEDs had high catalytic activities and good stereoselectivities. The melt flow rate (MFR) and gel permeation chromatography (GPC) results revealed that the obtained polypropylene has higher MFR and lower average molecular weights than the commercial EED cyclohexyl methyl dimethoxysilane. The differential scanning calorimetry (DSC) results indicated that new isospecific active centers formed after the introduction of new external donors. The work implied that the novel EEDs could improve the hydrogen sensitivities of the catalyst system and obtain polymers with high melt flow rate.
\end{abstract}

Keywords: Ziegler-Natta catalyst; external electron donor; isotactic polypropylene; high melt flow rate polypropylene

\section{Introduction}

Polypropylene plays an important role in life and industry due to its excellent physical properties, such as high stiffness, tensile strength, transparency, and low production cost [1-4]. Despite the rapid growth of single site catalysts, Ziegler-Natta catalysts still hold the dominant position in the production of polypropylene. Usually, in a typical $\mathrm{MgCl}_{2}$ supported catalyst, an internal electron donor (IED) such as di-n-butylphthlate (DNBP) and an external electron donor (EED) such as cyclohexyl methyl dimethoxysilane (CHMDMS) are often employed. It has been reported that the molecular structure and performance of polypropylene can be controlled by IED and EED [5-7]. Specifically, an electron donor (ED) is generally used to improve stereoselectivity for propylene polymerization [8-13]. Although countless potential organic compounds have been tested as IEDs and EEDs, only a few combinations between IEDs and EEDs were found to give satisfactory results [14,15]. Therefore, novel IED-EED combinations with simple structure are still needed to be studied to obtain Ziegler-Natta catalysts for the production of high isotactic polypropylene. 
Besides, processability of the polymer is important in the production of polypropylene. The polypropylene products with high MFR-which are easy to process and helpful to improve manufacturing speed-are appreciated by more and more manufacturers. The production of isotactic polypropylene (iPP) with high melt flow rate (MFR) was schematized in the China manufacturing 2025 plan. So far, polypropylene products with good flowability are mainly produced through two methods: degradation by peroxide [16,17], and direct polymerization using novel catalysts with good hydrogen sensitivities $[18,19]$. The degradation method is to add a peroxide degradation agent to decrease the molecular weight during the reaction. However, the peroxide compounds often have an unbearable smell. In addition, the added chemical agents can result in polymer degradation to some extent. So, this technique is hardly adopted when high quality is required. Meanwhile, the direct polymerization method is being used to produce high MFR isotactic polypropylene in commercial industries. By using novel catalyst with good hydrogen sensitivity, this method can produce high MFR polypropylene with high quality and low cost. Hydrogen sensitivity-referring to the response of the molecular weight and MFR of the polymer to hydrogen regulation in polymerization-is a very important character of Ziegler-Natta catalysts. Usually, good-hydrogen-sensitivity catalysts can be prepared by adding novel IEDs or EEDs. Takefumi reported that polypropylene with high melt flow rate $\left(M F R \geq 25 \mathrm{~g} / 10 \mathrm{~min}\right.$ ) was obtained through $\left(\mathrm{R}^{1} \mathrm{R}^{2} \mathrm{~N}\right)_{\mathrm{m}}\left(\mathrm{R}^{3} \mathrm{HN}\right)_{\mathrm{n}} \mathrm{R}_{\mathrm{p}}^{4} \mathrm{Si}\left(\mathrm{OR}^{5}\right)_{\mathrm{q}}$ as external electron donor based on magnesium chloride, magnesium ethylate, and magnesium powder supported $\mathrm{Mg}-\mathrm{Ti}$ catalysts [20]. Fina technology company utilized 2,2-diisobutyl-1,3-dimethoxy propane (DIBDP) as EED and Mg-Ti supported catalyst using phthalate as IED to prepare polypropylene with MFR up to $67.5 \mathrm{~g} / 10 \mathrm{~min}$ [21].

In the previous research, we synthesized four kinds of alkoxy silane compounds employed as IEDs for ethylene polymerization to obtain broad molecular weight distribution by the heterogeneous Ziegler-Natta catalysts via one-pot strategy [22]. In the present research, two kinds of novel cyclo alkoxy silane compounds were synthesized and employed as EEDs based on the spherical $\mathrm{MgCl}_{2}$ supported Ziegler-Natta catalysts. Diethyl 2,3-diisopropylsuccinate was employed as IED, which has good hydrogen sensitivity in propylene polymerization. The polymerization results showed that the high isotacticity polypropylene was prepared using these EEDs. It was also found that the novel EEDs could improve the hydrogen sensitivity of the catalyst system and obtain polymers with high melt flow rate. The effects of EED amount on polymerization behaviors were also discussed. The obtained polypropylene was also characterized by differential scanning calorimetry (DSC) and Fourier transform infrared spectroscopy (FT-IR).

\section{Materials and Methods}

\subsection{Materials}

Tetraethoxysilane, $\mathrm{Si}(\mathrm{OEt})_{3} \mathrm{Cl}$, cyclopentanol, cyclohexanol, 2-ethylhexanol, anhydrous magnesium chloride, and $\mathrm{AlEt}_{3}$ with $1.0 \mathrm{M}$ in hexane were purchased from Acros Organics Agent in Beijing, China. Triethylamine, anhydrous ethanol, alcohol, hydrochloric acid, $\mathrm{TiCl}_{4}$, toluene, $n$-heptane, and $n$-hexane were purchased from Beijing Chemicals Company (Beijing, China). Toluene and $n$-hexane were further purified by refluxing over sodium under normal pressure for $48 \mathrm{~h}$ prior to use. All kinds of alcohols were treated with activated $5 \AA$ molecular sieves under high purity nitrogen atmosphere for one week before use. Decane was purchased from Beijing Chemical Industry Company Ltd. (Beijing, China). Ethylene and propylene (polymerization grade) from Beijing Guangming Chemical and Engineering Company Ltd. (Beijing, China) was used without further purification.

\subsection{Propylene Bulk Polymerization}

All polymerization manipulations were carried out in a $5 \mathrm{~L}$ autoclave after purging all moisture and oxygen by a high-vacuum pump. The desired amount of cocatalyst $\mathrm{AlEt}_{3}$, hexane solution of external electron donor, and catalyst were added into the reactor in order at $30^{\circ} \mathrm{C}$. After that, hydrogen 
was introduced into the vessel. Then, $2.3 \mathrm{~L}$ propylene was added into the vessel at $30{ }^{\circ} \mathrm{C}$. After $5 \mathrm{~min}$ of pre-polymerization, the temperature of the system was raised to $70^{\circ} \mathrm{C}$. The polymerization occurred at $70{ }^{\circ} \mathrm{C}$ for $1 \mathrm{~h}$. Finally, the reaction was stopped, and the obtained product was dried to constant weight in a vacuum oven at $50{ }^{\circ} \mathrm{C}$. The dry polypropylene was weighed, and the catalytic activity was calculated.

\subsection{Characterization}

${ }^{1} \mathrm{H}$ NMR spectra were recorded on a Varian INOVA $600 \mathrm{MHz}$ spectrometer (Varian, Palo Alto, CA, USA) in $\mathrm{CDCl}_{3}$ solution at $25^{\circ} \mathrm{C}$, and tetramethylsilane was used as reference. All ${ }^{1} \mathrm{H}$ chemical shifts were reported in ppm relative to proton resonance in $\mathrm{CDCl}_{3}$ at $\delta 7.26 \mathrm{ppm}$. Elemental analyses were performed on a Perkin-Elmer 2400 microanalyzer (Perkin-Elmer, Waltham, MA, USA). Ti content of catalyst was measured by Shimadzu ICPS-5000 (Shimadzu, Kyoto, Japan). About $10 \mathrm{mg}$ of the supported catalyst was completely dissolved with $\mathrm{HF}$ and $\mathrm{HNO}_{3}$ acid. The solution was diluted with distilled water and used for the ICP-AES analysis. FT-IR spectra were recorded by a Nicolet 5DXC FT-IR spectrograph (Nicolet, Madison, AL, USA). The spectra were obtained at a $40 \mathrm{~cm}^{-1}$ resolution, and average data were obtained from at least 32 scans in the standard wave number range from 500 to $4000 \mathrm{~cm}^{-1}$. The average molecular weight and molecular weight distribution were measured by PL-GPC200 instrument (Varian, Palo Alto, CA, USA) using standard polyethylene as reference and 1,2,4-trichlorobenzene as solvent at $150^{\circ} \mathrm{C}$. DSC thermograms were recorded with a PA5000-DSC instrument (Perkin-Elmer, Munich, Germany) at a rate of $10 \mathrm{~K} / \mathrm{min}$. Melt flow rate was measured through GOETTFERT mi-4 melt indexer (GOETTFERT, Buchen, Germany) with diameter of $2.095 \mathrm{~mm}$ and die of $8 \mathrm{~mm}$. The isotacticity index (II) of polypropylene was determined through extraction of the sample by boiling $n$-heptane in a soxhlet extractor for $8 \mathrm{~h}$. The weight percentage of the insoluble portion was taken as the II value.

\subsection{Preparation of Electron Donors}

The synthesis of electron donors (ED1 as example) were carried out as Scheme 1.

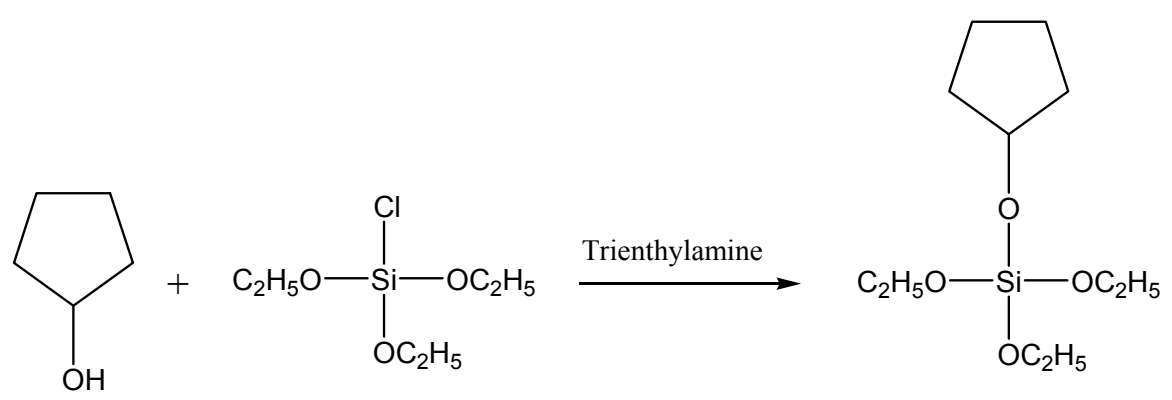

Scheme 1. Synthesis of electron donors (ED).

Preparation of ED1. Under nitrogen atmosphere, the solution of $1.0 \mathrm{~mL}$ cyclopentanol in $100 \mathrm{~mL}$ $n$-hexane was added into $300 \mathrm{~mL}$ Schlenk flask with a stirring bar. After $1.5 \mathrm{~mL}$ triethylamine and $2.2 \mathrm{~mL} \mathrm{Si}(\mathrm{OEt})_{3} \mathrm{Cl}$ were dripped slowly into the reactor in order by a syringe at room temperature, the mixture was stirred for $2 \mathrm{~h}$ at room temperature. After filtering the mixture, the filtrate was purified by vacuum to get a colorless transparent liquid, triethoxy cyclopentyloxy silane (ED1) with yield of $87.3 \mathrm{wt} \%$. ED1, $\mathrm{C}_{11} \mathrm{H}_{24} \mathrm{O}_{4} \mathrm{Si}\left(\mathrm{M}_{\mathrm{W}}, 248 \mathrm{~g} / \mathrm{mol}\right){ }^{1} \mathrm{H}$ NMR (Figure 1): $\delta 1.24$ (tri, $\left.9 \mathrm{H}-\mathrm{OCH}_{2} \mathrm{CH}_{3}\right) ; \delta 1.51$ $\left(\mathrm{m}, 2 \mathrm{H}-\mathrm{CH}_{2} \mathrm{CH}_{2} \mathrm{CH}_{2} \mathrm{CH}_{2}-\right) ; \delta 1.68\left(\mathrm{~m}, 2 \mathrm{H}-\mathrm{CH}_{2} \mathrm{CH}_{2} \mathrm{CH}_{2} \mathrm{CH}_{2}-\right) ; \delta 1.75\left(\mathrm{~m}, 4 \mathrm{H}-\mathrm{CH}_{2} \mathrm{CH}_{2} \mathrm{CH}_{2} \mathrm{CH}_{2}-\right.$ ); $\delta 3.85\left(\mathrm{q}, 6 \mathrm{H}-\mathrm{OCH}_{2} \mathrm{CH}_{3}\right) ; \delta 4.98(\mathrm{~m}, 1 \mathrm{H}-\mathrm{CH}(\mathrm{O})-)$. $\mathrm{E}_{\mathrm{LEM}}$. A $\mathrm{A}_{\mathrm{NAL}}$. Calcd: C, 53.23; H, 9.68; O, 25.81. Found: C, 53.21; H, 9.67; O, 25.80. 


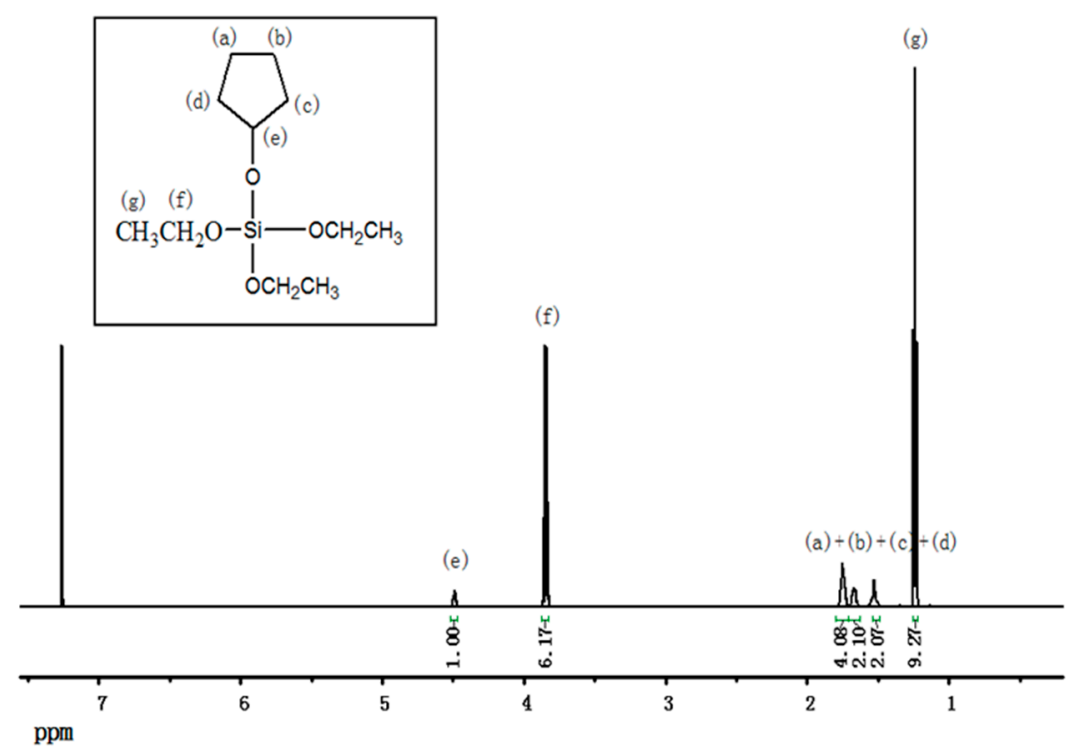

Figure 1. ${ }^{1} \mathrm{H}$ NMR spectrum of ED1.

Preparation of ED2. Under nitrogen atmosphere, the solution of $1.0 \mathrm{~mL}$ cyclohexanol in $100 \mathrm{~mL}$ $n$-hexane was added into a $300 \mathrm{~mL}$ Schlenk flask with a stirring bar. After $1.3 \mathrm{~mL}$ triethylamine and $1.9 \mathrm{~mL} \mathrm{Si}(\mathrm{OEt})_{3} \mathrm{Cl}$ were dripped slowly into the reactor in order by a syringe at room temperature, the mixture was stirred for $2 \mathrm{~h}$ at room temperature. After filtering the mixture, the filtrate was purified by vacuum to get a colorless transparent liquid, triethoxy cyclohexyloxy silane (ED2) with yield of 90.7 wt \%. ED2, $\mathrm{C}_{12} \mathrm{H}_{26} \mathrm{O}_{4} \mathrm{Si}\left(M_{\mathrm{W}}, 262 \mathrm{~g} / \mathrm{mol}\right),{ }^{1} \mathrm{H}$ NMR (Figure 2): $\delta 1.20\left(\mathrm{~m}, 1 \mathrm{H}-\mathrm{CH}_{2} \mathrm{CH}_{2} \mathrm{CH}_{2} \mathrm{CH}_{2} \mathrm{CH}_{2}-\mathrm{CH}(\mathrm{O})-\right) ; \delta 1.24$ (tri, 9H - $\left.\mathrm{OCH}_{2} \mathrm{CH}_{3}\right) ; \delta 1.32-1.40(\mathrm{~m}, 4 \mathrm{H}$ $\left.-\mathrm{CH}_{2} \mathrm{CH}_{2} \mathrm{CH}_{2} \mathrm{CH}_{2} \mathrm{CH}_{2}-\mathrm{CH}(\mathrm{O})-\right) ; \delta 1.51\left(\mathrm{~m}, 1 \mathrm{H}-\mathrm{CH}_{2} \mathrm{CH}_{2} \mathrm{CH}_{2} \mathrm{CH}_{2} \mathrm{CH}_{2}-\mathrm{CH}(\mathrm{O})-\right) ; \delta 1.75-1.87(\mathrm{~m}$, $\left.4 \mathrm{H}-\mathrm{CH}_{2} \mathrm{CH}_{2} \mathrm{CH}_{2} \mathrm{CH}_{2} \mathrm{CH}_{2}-\mathrm{CH}(\mathrm{O})-\right) ; \delta 3.85$ (q, $\left.6 \mathrm{H}-\mathrm{OCH}_{2} \mathrm{CH}_{3}\right) ; \delta 3.81(\mathrm{~m}, 1 \mathrm{H}-\mathrm{CH}(\mathrm{O})-)$. E EEM. A A Calcd: C, 54.96; H, 9.92; O, 24.43. Found: C, 54.95; H, 9.90; O, 24.41.
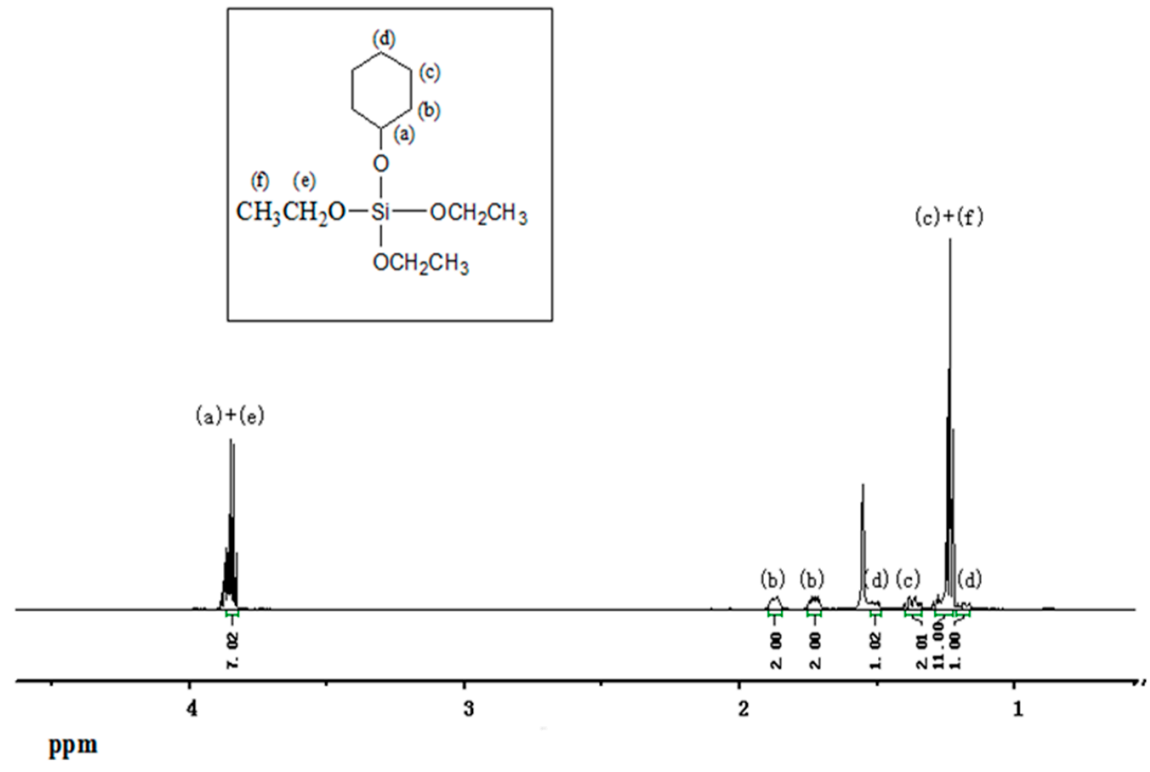

Figure $2 .{ }^{1} \mathrm{H}$ NMR spectrum of ED2.

ED3 is cyclohexyl methyl dimethoxysilane (CHMDMS), which is a mature commercial EED most commonly used in propylene polymerization process. It was prepared according to the patent [23]. 


\subsection{Preparation of the Catalysts}

$\mathrm{MgCl}_{2}(1.0 \mathrm{~g})$ and anhydrous ethanol $(20 \mathrm{~mL})$ were added into $300 \mathrm{~mL}$ Schlenk flask at room temperature with a stirring bar. The mixture was warmed to $80^{\circ} \mathrm{C}$ and kept for $2 \mathrm{~h}$, and then transferred into $n$-hexane solution of vacuum grease while hot. After stirring for $20 \mathrm{~min}$, the mixture was filtered, and the residue was washed with $n$-hexane $(20 \mathrm{~mL} \times 3)$. The obtained solid was dried by vacuum to get a white powder spherical support with a yield of $2.45 \mathrm{~g}$. Its component consisted of $\mathrm{MgCl}_{2} \cdot 3.5 \mathrm{C}_{2} \mathrm{H}_{5} \mathrm{OH}$ as determined by micro analysis [24].

Spherical support $(1.0 \mathrm{~g})$ was suspended in $50 \mathrm{~mL}$ hexane. While stirring, $10 \mathrm{~mL} \mathrm{TiCl} 4$ was dripped into the system at $-10^{\circ} \mathrm{C}$. It was slowly warmed to $60^{\circ} \mathrm{C}$, and the desired amount of diethyl 2,3-diisopropylsuccinate was added into the flask. The reaction lasted for $3 \mathrm{~h}$. The obtained residue after filtering was washed with $n$-hexane $(20 \mathrm{~mL} \times 3)$. A brown powder catalyst was obtained with a yield of $0.66 \mathrm{~g}$. The catalyst composition and its principal physical parameters are as follows: $\mathrm{Ti}$ content of the catalyst $2.8 \mathrm{wt} \%$ determined by ICP-AES, the average diameter of spherical particles $45 \mu \mathrm{m}$, the specific surface area $\sim 130 \mathrm{~m}^{2} / \mathrm{g}$.

\section{Results and Discussion}

The two novel alkoxy silane compounds (ED1 and ED2) and ED3 were used as EEDs for propylene polymerization. Polymerization results are compiled in Table 1. As shown in Table 1, the catalyst systems with ED1 and ED2 as EEDs had high catalytic activities, which were almost the same as ED3. The catalytic activities of catalysts with ED1, ED2, or ED3 as EEDs were lower than that without EED (run 7 and 8). This fact can be attributed to selective positions of EEDs, which suppress reactivity of the aspecific centers and may convert the aspecific centers into isospecific ones [25]. Moreover, with increasing hydrogen concentration, catalyst activities increased in all cases, as chain transfer with hydrogen leads to the regeneration of isospecific propagation [26-28].

Table 1. Results of propylene polymerization catalyzed by $\mathrm{TiCl}_{4} / \mathrm{IED} / \mathrm{MgCl}_{2} / \mathrm{EED}$ catalyst system.

\begin{tabular}{cccccccc}
\hline Run & EED & $\begin{array}{c}\mathbf{H}_{\mathbf{2}} \\
\mathbf{( M P a})\end{array}$ & $\mathbf{A}^{\mathbf{a}} \times \mathbf{1 0}^{-\mathbf{3}}$ & $\mathbf{I I}^{\mathbf{b}} \mathbf{( \% )}$ & $A_{\mathbf{9 9 8}} / \mathbf{A}_{\mathbf{9 7 3}}$ & $\mathbf{I I}^{\mathbf{c}} \mathbf{( \% )}$ & $\begin{array}{c}\mathbf{M F R}^{\mathbf{d}} \\
\mathbf{( g / 1 0} \mathbf{m i n})\end{array}$ \\
\hline 1 & \multirow{2}{*}{ ED1 } & 0.1 & 10.4 & 98.6 & 0.916 & 98.7 & 25 \\
2 & 0.2 & 12.5 & 98.3 & 0.911 & 98.2 & 120 \\
\hline 3 & \multirow{2}{*}{ ED2 } & 0.1 & 10.9 & 97.6 & 0.908 & 98.0 & 29 \\
4 & 0.2 & 12.7 & 98.2 & 0.904 & 97.6 & 121 \\
\hline 5 & \multirow{2}{*}{ ED3 } & 0.1 & 10.1 & 97.8 & 0.909 & 98.1 & 7 \\
\hline 7 & 0.2 & 12.2 & 98.3 & 0.907 & 97.9 & 12 \\
\hline 8 & & 0.1 & 12.4 & 81.1 & 0.727 & 81.2 & 9 \\
\hline
\end{tabular}

Polymerization conditions: catalyst, Ti content $2.8 \mathrm{wt} \%, 20 \mathrm{mg}$; propylene, $2.3 \mathrm{~L}$; temperature, $70{ }^{\circ} \mathrm{C}$; time, $1 \mathrm{~h} ; n(\mathrm{Al}) / n(\mathrm{Ti})=500: 1{ }^{\mathrm{a}}$ the catalytic activity, $(\mathrm{g} \mathrm{PP}) \cdot(\mathrm{g} \mathrm{cat})^{-1} \cdot \mathrm{h}^{-1}$; $\mathrm{b}$ isotactic index calculated by extraction of the sample with boiling $n$-heptane in a soxhlet extractor; ${ }^{c}$ isotactic index calculated by Fourier transform infrared spectroscopy (FT-IR); ${ }^{\mathrm{d}}$ melt flow rate determined by Melt indexer at $2.16 \mathrm{~kg}$ and $230{ }^{\circ} \mathrm{C}$. EED: external electron donor.

From Table 1, we can find that the melt flow rates of the obtained iPPs catalyzed by catalysts with novel EED were much larger than expected. When 0.2 MPa hydrogen was added, the MFR of the polypropylene produced by the catalyst with commercial ED3 as EED was $17 \mathrm{~g} / 10 \mathrm{~min}$, whereas the MFR of that with ED1 and ED2 were higher than $120 \mathrm{~g} / 10 \mathrm{~min}$. When ED1 or ED2 were used as EED for propylene polymerization, all the resulted polymers had much higher MFR than ED3. The MFR results suggested that the catalysts with ED1 or ED2 as EED had very good hydrogen sensitivities, which were much better than that with the commercial ED3. This means the novel EEDs could improve the hydrogen sensitivity of the catalyst system and obtain polymers with high melt flow rate. These results 
affirmed that the hydrogen sensitivity of the catalyst system can be improved by the employment of novel EEDs. Specifically, it is generally believed that there are diversified ways in which donors containing two oxygen atoms coordinate with $\mathrm{MgCl}_{2}$ [29]. Different from the traditional EEDs, such as ED3 (CHMDMS), dicyclopentyl dimethoxysilane (DCPDMS), diisobutyl dimethoxysilane (DIBDMS), and diisopropyl dimethoxysilane (DIPDMS) [30], the EEDs synthesized in this work contain four oxygen atoms, which resulted in an accumulation of excess electrons around $\mathrm{MgCl}_{2}$ molecules, and thus weakened the coordination ability with $\mathrm{TiCl}_{4}$ molecules. The accumulation of excess electrons may increase the odds of 2, 1 insertion, thus leading to the improvement of hydrogen sensitivities [31].

Usually, a polymer with high $M_{\mathrm{w}}$ often has stronger intermolecular interaction, which results in higher viscosity and low MFR [32]. On the other hand, a polymer with high MFR often features low molecular weight or broad molecular weight distribution. The GPC result was presented in Figure 3. The obtained polypropylene catalyzed by catalysts with ED1/ED2 as EED had lower average molecular weight than that with ED3 as EED, implying that these catalyst systems using ED1/ED2 as EED had better hydrogen sensitivities. GPC results agreed with the MFR results.

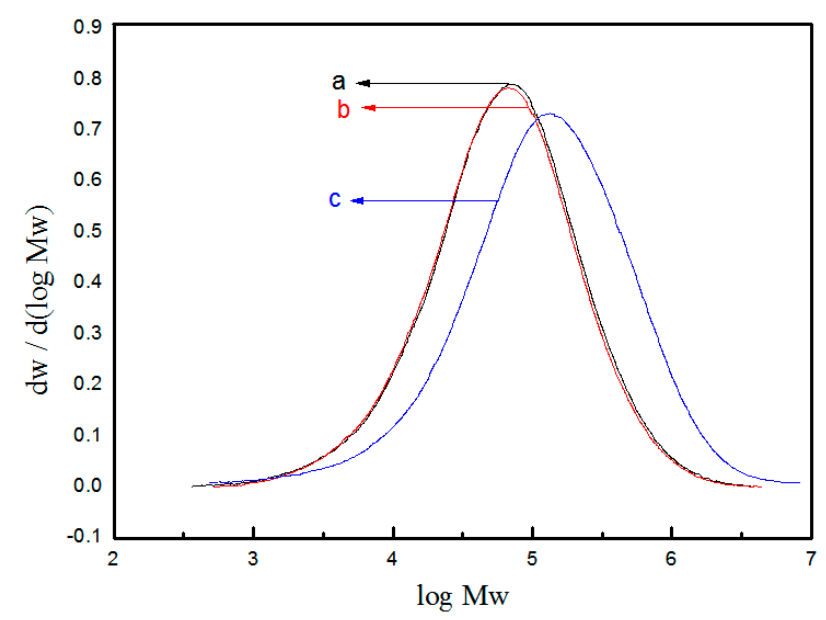

Figure 3. GPC curves of isotactic polypropylene (iPP) (a with ED1, b with ED2, and $\mathbf{c}$ with ED3).

The isotacticity of polypropylene was a remarkable characteristic of iPP. The most commonly used catalyst system for iPP in industry contains phthalate as IED and alkoxy silane as EED. ED3 is a typical commercial alkoxy silane EED, most commonly used in the propylene polymerization process. As shown in Table 1, all the isotacticities of iPP catalyzed by the catalyst systems using ED1 and ED2 as EEDs were higher than $97.6 \%$, which were nearly the same as ED3 and higher than that without adding an EED in the catalyst system. This means that the novel alkoxy silane external electron donor has a certain positive role, improving the stability and the selectivity of active centers of the catalyst systems.

The microstructure of the obtained polypropylene was characterized by FT-IR. Burfield and Loi reported that the isotactic index could be also determined by the following equation [33]:

$$
\frac{A_{998}}{A_{973}}=1.08(\text { II })-0.15,
$$

where $A_{998}$ is the area of the peak at $998 \mathrm{~cm}^{-1}$ in the FT-IR spectra, $A_{973}$ is the absorbance area of the peak at $973 \mathrm{~cm}^{-1}$, and II is the isotactic index.

The FT-IR results of the resultant iPPs showed that $A_{998} / A_{973}$ ratios were from 0.904 to 0.916 , corresponding to the isotactic index from $97.6 \%$ to $98.7 \%$ (Table 1 ). The polypropylene catalyzed by the catalyst system without EED exhibited a lower isotactic index of $79.0 \%$. All of the results are consistent with that obtained by soxhlet extraction method. The results confirmed that ED1, ED2, and ED3 as EEDs were effective to improve the stereoselectivity in propylene polymerization. 
The titanium-based Ziegler-Natta catalysts are heterogeneous catalysts. They have two types of active centers: isospecific and aspecific. The former produces highly crystalline isotactic polypropylene, and the latter results in amorphous atactic polypropylene. As far as isospecific centers are concerned, they can be divided into several populations of active centers which have different stereospecificity control [34]. Different isospecific centers show different stereoselectivity, chain propagation rate, and chain transfer rate to propylene and Hydrogen. Thus, polypropylene with different isotacticity index, melting point, and molecular weight are produced in polymerization. As a result, the more isospecific centers the catalysts possess, the broader the melting curves of DSC become. From the DSC analysis results shown in Figure 4, we can find that the obtained polypropylene catalyzed by catalyst with ED1/ED2/ED3 as EED all possessed high melting points (curves a, b, and c in Figure 4). This implies that ED1 and ED2-similar to ED3—were favorable for propylene polymerization to form highly isotactic polypropylene. However, the shapes of curves $\mathrm{a}$ and $\mathrm{b}$ are slightly different from curve c, suggesting that the polymer microstructures are different. The melting curves a and $\mathrm{b}$ are broader than curve c. Shoulder peaks in curves $\mathrm{a}$ and $\mathrm{b}$ are observed, but do not appear in curve c. It is possible that the new isospecific active centers are formed after the introduction of new external donors. Considering that the polymers catalyzed by catalysts with ED1/ED2 as EED had lower average molecular weight and higher MFR than ED3, the newly formed isospecific active center may have higher chain transfer rate to hydrogen.

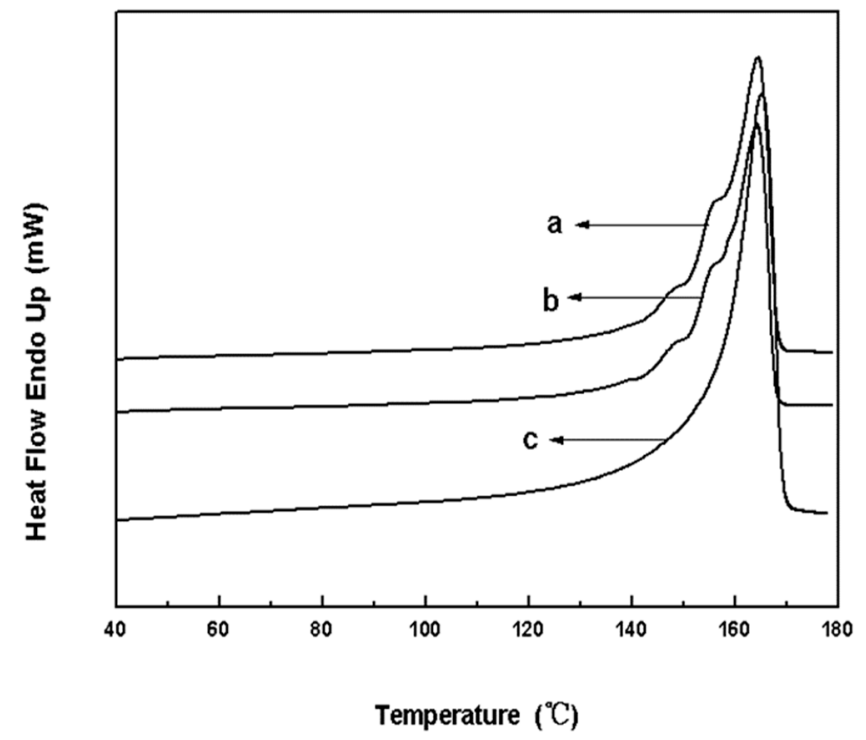

Figure 4. Differential scanning calorimetry (DSC) curves of iPP (a with ED1, b with ED2, and $\mathbf{c}$ with ED3).

The catalytic activity and isotacticity results indicated that the performances of ED1 and ED2 were basically at the same level as ED3, which is a mature commercial EED. This means that ED1 and ED2 are qualified as EEDs. The performance of alkoxy silane as EED is affected by the number of alkoxy groups, size, and nature of the substituent bonded to the silicon atom [35,36]. As far as the EEDs we adopted, the abundant alkoxy groups could block the aspecific sites on the $\mathrm{MgCl}_{2}$ layers through competitive complexation and transformation of aspecific into isospecific sites [37-39], and even facilitate the formation of new isospecific active sites [40], which contributed to an increase in the stereoregularity of the resultant iPP.

Moreover, the catalysts with ED1 or ED2 as EED exhibited excellent hydrogen sensitivities. When catalysts with good hydrogen sensitivity are used in industrial units, the molecular weight of the polymer can be adjusted by hydrogen in a larger range. This is very meaningful to industrial production: the hydrogen consumption can be reduced, the products can be processed more easily, 
the manufacturing speed of products can be increased, and more new high-performance polyolefin products can be produced.

\section{Conclusions}

In this research, two kinds of novel cyclol-based alkoxy silane compounds were synthesized and used as external electron donor (EED) to investigate propylene polymerization based on a $\mathrm{MgCl}_{2} / \mathrm{TiCl}_{4} /$ diethyl 2,3-diisopropylsuccinate catalyst system. The results confirmed that the catalytic activities and stereoselectivities of catalyst systems with ED1 and ED2 as EEDs were as good as the catalyst with commercial ED3 as EED. The work implied that the novel EEDs could improve the hydrogen sensitivities of the catalyst system and obtain polymers with high melt flow rate. In the near future, the two EEDs will be applied in a pilot polymerization plant of $75 \mathrm{~kg} / \mathrm{h}$ to verify the effectiveness of improving hydrogen sensitivities, then the two novel EEDs are hopeful to be used in the polypropylene industry. With the market demand growth of high melt flow rate polypropylene, the two EEDs may play an important role for the development of high performance polypropylene.

Acknowledgments: We sincerely thank the National Natural Science Foundation of China (No. U1462102) and Petrochina (No. 2010C-3715).

Author Contributions: The experimental work was conceived and designed by Qigu Huang, Jianjun Yi, Hongming Li, and Wantai Yang; Hongming Li, Jing Wang, Lei He, Feng Nan, Fan Wang performed the experiments; Qigu Huang, Hongming Li, Mingge Zhang, Tianxu Sun and Weisong Cui analyzed the data; Jianjun Yi, Jian Wang, and Hongming Li contributed reagents/materials/analysis tools; Hongming Li and Qigu Huang drafted the paper. The manuscript was amended through the comments of all authors. All authors have given approval for the final version of the manuscript.

Conflicts of Interest: The authors declared no conflicts of interest.

\section{References}

1. Sacchi, M.C.; Forlini, F.; Tritto, I.; Locatelli, P.; Morrini, G.; Noristi, L.; Albizzati, E. Polymerization stereochemistry with Ziegler-Natta catalysts containing dialkylpropane diethers: A tool for understanding internal/external donor relationships. Macromolecules 1996, 29, 3341-3345. [CrossRef]

2. Morrini, G.; Albizzati, E.; Balbontin, G.; Mingozzi, I.; Sacchi, M.C.; Forlini, F.; Tritto, I. Microstructure distribution of polypropylenes obtained in the presence of traditional phthalate/silane and novel diether donors: A tool for understanding the role of electron donors in $\mathrm{MgCl}_{2}$-supported Ziegler-Natta catalysts. Macromolecules 1996, 29, 5770-5776. [CrossRef]

3. Soga, K.; Shiono, T. Ziegler-Natta catalysts for olefin polymerizations. Prog. Polym. Sci. 1997, 22, 1503-1546. [CrossRef]

4. Dusseault, J.J.A.; Hsu, C.C. $\mathrm{MgCl}_{2}$-supported Ziegler-Natta catalysts for olefin polymerization: Basic structure, mechanism, and kinetic behavior. Polym. Rev. 1993, 2, 103-145.

5. Tanase, S.; Katayama, K.; Yabunouchi, N.; Sadashima, T.; Tomotsu, N. Design of novel malonates as internal donors for $\mathrm{MgCl}_{2}$-supported $\mathrm{TiCl}_{4}$ type polypropylene catalysts and their mechanistic aspects, Part 1. J. Mol. Catal. A Chem. 2007, 273, 211-217. [CrossRef]

6. Vestberg, T.; Denifl, P.; Parkinson, M.; Wilén, C.E. Effects of external donors and hydrogen concentration on oligomer formation and chain end distribution in propylene polymerization with Ziegler-Natta catalysts. J. Polym. Sci. Pol. Chem. 2010, 48, 351-358. [CrossRef]

7. Nikolaeva, M.; Mikenas, T.; Matsko, M.; Zakharov, V. Effect of $\mathrm{AlEt}_{3}$ and an external donor on the distribution of active sites according to their stereospecificity in propylene polymerization over $\mathrm{TiCl}_{4} / \mathrm{MgCl}_{2}$ catalysts with different titanium content. Macromol. Chem. Phys. 2016, 217, 1384-1395. [CrossRef]

8. Kaushik, V.K.; Gupta, V.K.; Patil, H.; Naik, D.G. Role of electron donor in polymer catalyst synthesis: An XPS study. Catal. Lett. 2008, 121, 58-62. [CrossRef]

9. Zhang, H.X.; Lee, Y.J.; Park, J.R.; Lee, D.H.; Yoon, K.B. Control of molecular weight distribution for polypropylene obtained by commercial Ziegler-Natta catalyst: Effect of electron donor. Macromolecules 2011, 19, 622-628. [CrossRef] 
10. Sacchi, M.C.; Forlini, F.; Tritto, I.; Locatelli, P. Stereochemistry of the initiation step in Ziegler-Natta catalysts containing dialkyl propane diethers: A tool for distinguishing the role of internal and external donors. Macromol. Symp. 1995, 89, 91-100. [CrossRef]

11. Batt-Coutrot, D.; Wolf, V.; Malinge, J.; Saudemont, T.; Grison, C. Study of dimethoxysilacycloalkanes as external donors in Ziegler-Natta stereospecific propylene polymerisation. Polym. Bull. 2005, 54, $377-385$. [CrossRef]

12. Alshaiban, A.; Soares, J.B.P. Effect of varying hydrogen concentration, external donor concentration, and temperature on propylene polymerization kinetics and microstructure of polypropylene made with a 4 th generation Ziegler-Natta Catalyst. Macromol. React. Eng. 2014, 8, 723-735. [CrossRef]

13. Alshaiban, A.; Soares, J.B.P. Effect of hydrogen and external donor on propylene polymerization kinetics with a 4th-generation Ziegler-Natta catalyst. Macromol. React. Eng. 2012, 6, 265-274. [CrossRef]

14. Massimiliano, T.; Morini, G.; Guerra, G.; Corradini, P.; Cavallo, L. Influence of 1,3-diethers on the stereospecificity of propene polymerization by supported Ziegler-Natta catalysts. A theoretical investigation on their adsorption on (110) and (100) lateral cuts of $\mathrm{MgCl}_{2}$ platelets. Macromolecules 2000, 33, 1134-1140.

15. Thorman, J.L.; Blackmon, K.P. Novel Combinations of Silane Electron Donors for Use in Catalyst Compositions. U.S. Patent 20060252894, 9 November 2006.

16. Resconi, L.; Cavallo, L.; Fait, A.; Peimontesi, F. Selectivity in propene polymerization with metallocene catalysts. Chem. Rev. 2000, 100, 1253. [CrossRef] [PubMed]

17. Serena, C.; Elisa, P.; Mauro, A.; Francesco, C. Control of degradation reactions during radical functionalization of polypropylene in the melt. Macromolecules 2004, 37, 8414-8423.

18. Blackmon, K.P. Production of Ultra High Melt Flow Polypropylene Resins. Eur. Patent 1,223,181, 17 July 2002.

19. Musgrave, M.W. Pelletized Polyolefin Having Ultra-High Melt Flow and Its Articles of Manufacture. U.S. Patent 6,423,800, 23 July 2002.

20. Takefumi, Y.; Motoki, H.; Maki, S. Catalyst Component and Catalyst for Olefin Polymerization and Method for Producing Olefin Polymer Using Those. U.S. Patent 8,247,504, 15 February 2007.

21. Bauch, C.G. Polymerization of Olefins Using a Ziegler-Natta Catalyst System Having an External Electron Donor. U.S. Patent 6,818,711, 1 July 2004.

22. Liu, Z.; Zhang, X.L.; Huang, H.B.; Yi, J.J.; Huang, Q.G.; Yang, W.T. Synthesis of (co-)polyethylene with broad molecular weight distribution by the heterogeneous Ziegler-Natta catalysts via one-pot strategy. J. Ind. Eng. Chem. 2012, 18, 2217-2224. [CrossRef]

23. Endo, M.; Takamizawa, M.; Ishihara, T. A Method for the Preparation of a Cycloalkyl Silane Compound. U.S. Patent 4,957,607, 17 August 1988.

24. Huang, Q.G.; Liu, W.J.; Dou, X.L.; Zhang, X.L.; Kong, Y.; Yang, W.T. Preparation Method and Application of Spherical Magnesium Halide Carrier. CN Patent 101,955,556, 26 January 2010.

25. Garoff, T.; Virkkunen, V.; Jaaskelainen, P.; Vestberg, T. A qualitative model for polymerisation of propylene with a $\mathrm{MgCl}_{2}$-supported $\mathrm{TiCl}_{4}$ Ziegler-Natta catalyst. Eur. Polym. J. 2003, 39, 1679-1685. [CrossRef]

26. Chadwick, J.C.; Morini, G.; Albizzati, E.; Balbontin, G.; Mingozzi, I.; Cristofori, A.; Sudmeijer, O.; van Kessel, G.M.M. Aspects of hydrogen activation in propene polymerization using $\mathrm{MgCl}_{2} / \mathrm{TiCl}_{4} /$ diether catalysts. Macromol. Chem. Phys. 1996, 197, 2501-2510. [CrossRef]

27. Chadwick, J.C.; Morini, G. Aspects of hydrogen activation in propene polymerization using $\mathrm{MgCl}_{2} / \mathrm{TiCl}_{4} /$ diether catalysts. Macromol. Symp. 2001, 173, 21-36. [CrossRef]

28. Chadwick, J.C.; Morini, G.; Balbontin, G.; Camurati, I.; Heere, J.J.R.; Mingozzi, R.; Testoni, F. Effects of internal and external donors on the regio- and stereoselectivity of active species in $\mathrm{MgCl}_{2}$-supported catalysts for propene polymerization. Macromol. Chem. Phys. 2001, 202, 1995-2002. [CrossRef]

29. Seth, M.; Margl, P.M.; Ziegler, T. A density functional embedded cluster study of proposed active sites in heterogeneous Ziegler-Natta catalysts. Macromolecules 2002, 35, 7815-7829. [CrossRef]

30. Bai, X.; Gao, M.; Li, T. Effect of external donors on performance of $N$-catalyst in propylene polymerization. Petrochem. Technol. 2004, 34, 615-618.

31. Chadwick, J.C.; Kessel, G.; Sudmeijer, O. Regio- and stereospecificity in propene polymerization with $\mathrm{MgCl}_{2}$-supported Ziegler-Natta catalysts: Effects of hydrogen and the external donor. Macromol. Chem. Phys. 2003, 196, 1431-1437. [CrossRef]

32. Gui, Q.D.; Xin, Z.; Zhu, W.P.; Dai, Z. Effects of an organic phosphorus nucleating agent on crystallization behaviors and mechanical properties of poly(propylene). J. Appl. Polym. Sci. 2003, 88, 297-301. [CrossRef] 
33. Burfield, D.R.; Loi, P.S.T. The use of infrared spectroscopy for determination of polypropylene stereoregularity. J. Appl. Polym. Sci. 1988, 36, 279-293. [CrossRef]

34. Kissin, Y.V.; Zhou, Q.; Li, H.; Zhang, L. Active centers in propylene polymerization catalysts of the fourth generation. J. Catal. 2015, 332, 156-163. [CrossRef]

35. Proto, A.; Oliva, L.; Pellecchia, C.; Sivak, A.J.; Cullo, L. Isotactic-specific polymerization of propene with supported catalysts in the presence of different modifiers. Macromolecules 1990, 23, 2904-2907. [CrossRef]

36. Sacchi, M.C.; Forlini, F.; Tritto, I.; Mendichi, R.; Zannoni, G.; Noristi, L. Activation effect of alkoxysilanes as external donors in magnesium chloride-supported Ziegler-Natta catalysts. Macromolecules 1992, 25, 5914-5918. [CrossRef]

37. Kashiwa, N.; Yoahitake, J. Kinetic study on propylene polymerization with $\mathrm{MgCl}_{2} / \mathrm{TiCl}_{4}-\mathrm{AlEt}_{3} / \mathrm{PhCO}_{2} \mathrm{Et}$ System-The role of ethyl benzoate. Polym. Bull. 1984, 12, 99-104. [CrossRef]

38. Soga, K.; Shiono, T.; Doi, Y. Influence of internal and external donors on activity and stereospecificity of Ziegler-Natta catalysts. Makromol. Chem. 1988, 189, 1531-1541. [CrossRef]

39. Sacchi, M.C.; Tritto, I.; Locatelli, P. Stereochemical investigation of the effect of Lewis bases in heterogeneous Ziegler-Natta initiator systems. Prog. Polym. Sci. 1991, 16, 331-360. [CrossRef]

40. Harkkonen, M.; Seppala, J.V.; Chujo, R.; Kogure, Y. External silane donors in Ziegler-Natta catalysis: A two-site model simulation of the effects of various alkoxysilane compounds. Polymer 1995, 36, 1499-1505. [CrossRef]

(C) 2016 by the authors; licensee MDPI, Basel, Switzerland. This article is an open access article distributed under the terms and conditions of the Creative Commons Attribution (CC-BY) license (http://creativecommons.org/licenses/by/4.0/). 